\title{
Potential Drift of Pollen of Cycas micronesica on the Island of Guam: A Comparative Study
}

\author{
Trenton Hamada \\ College of Natural and Applied Sciences, Western Pacific Tropical Research \\ Center, University of Guam, UOG Station, Mangilao, GU
}

Irene Terry ${ }^{1}$

Department of Biology, University of Utah, 257 South 1400 East, Salt Lake City, UT

\section{Robert Roemer}

Department of Mechanical Engineering, University of Utah, Merrill Engineering Building, 50 S Central Campus Drive, Salt Lake City, UT

\author{
Thomas E. Marler \\ College of Natural and Applied Sciences, Western Pacific Tropical Research \\ Center, University of Guam, UOG Station, Mangilao, GU
}

Additional index words. ambophily, anemophily, entomophily, pollen settling velocity, trade winds

\begin{abstract}
We have investigated the potential movement on air currents of pollen from Guam's native cycad, Cycas micronesica, proposed as ambophilic. We measured wind velocities and directions in different cycad habitats that vary in their exposure to trade winds, determined pollen settling velocities, and then modeled the potential horizontal pollen drift distance in each habitat. Similar measurements were performed on several entomophilous Zamia cycads and six zoophilous tropical trees used in horticulture or landscaping. All cycad species' pollen exhibited relatively slow mean settling velocities $\left(0.73-1.29 \mathrm{~cm} \cdot \mathrm{s}^{-1}\right)$ with $C$. micronesica pollen in the middle of this range. Our models predicted that wind in more open habitats with wind directions east northeast (ENE) to northeast (NE) and velocities $>2 \mathrm{~m} \cdot \mathrm{s}^{-1}$ could transport $C$. micronesica pollen, either single grains or clumps, hundreds of meters downwind from the pollen source before falling 1 or $2 \mathrm{~m}$. In forested habitats and at typical heights of cycad cones in the understory, the mean wind velocities ranged from $<0.03 \mathrm{~m} \cdot \mathrm{s}^{-1}$ to $\approx 1 \mathrm{~m} \cdot \mathrm{s}^{-1}$. In habitats with mean winds $\geq 0.2 \mathrm{~m} \cdot \mathrm{s}^{-1}$, models predicted pollen transport distances of tens of meters from the pollen source. In sheltered habitats with velocities near $0.03 \mathrm{~m} \cdot \mathrm{s}^{-1}$, the potential wind transport of pollen was limited to less than a few meters, suggesting that wind would be an ineffective vector in such areas. Pollen grains of all angiosperm species were larger except one, and the species with larger grains had settling velocities 3-26 times faster than that of cycad pollens. Even so, winds in most Guam environments could transport pollen of most angiosperm species over $50 \mathrm{~m}$ before falling $1 \mathrm{~m}$. In summary, the results suggested that pollen size, clumping tendencies, and drift of most of these species do not preclude a role for wind in moving pollen in habitats exposed to trade winds, and that other physical and plant characteristics affect their pollination mode. For $C$. micronesica, these pollen and plant attributes do not preclude entomophily, and insects are likely required in the deep understory where cycads are present.
\end{abstract}

Numerous studies since the 1980s have demonstrated that plants within the Cycadales (cycads), an ancient lineage of dioecious gymnosperms, are entomophilous (Stevenson et al., 1998; Tang 2004), includ-

Received for publication 13 Jan. 2015. Accepted for publication 27 Apr. 2015.

Supported in part by USDA CSREES 2009-3413520096.

We thank M. Lander and A. Moore for loan of meteorological equipment and advice concerning Guam meteorology, and three anonymous reviewers for their helpful comments.

${ }^{1}$ To whom reprint requests should be addressed; e-mail irene.terry@utah.edu. ing species within the family Cycadaceae, a monogeneric family comprising $\approx 100$ Cycas species (Hall, 2011; Kono and Tobe, 2007). All cycad studies to date have shown that wind plays a minimal, if any, role as a pollen vector. A few questions remain concerning the pollination of some Cycas species, especially those in the species complex of the Rumphiae group (hereinafter referred to as Cycas rumphii species complex). These species, sometimes called 'island' cycads, are the only cycads that produce seeds with a specialized spongy section located between the sclerotesta and gametophyte that allows seeds to float in water (Dehgan and Yuen, 1983; Hill, 1994). Their distribution extends from Africa and Madagascar eastward through coastal southeast Asia, Indonesia, and many islands of the western Pacific. Questions about the pollination system in these species arise because some inhabit islands far from mainland cycad populations, and many of these do not have the insect pollinators found on mainland cycads (Hamada et al., 2015). In addition, some of these island species' ovules are more exposed to airborne pollen than ovules of other cycads.

The island of Guam began as submarine volcanic deposits in the Eocene $\approx 43$ million years ago (mya), but land mass aerial exposure occurred much later $\approx 21$ mya (Mylroie et al., 2001). The island's native flora is composed of tropical plants including cycads that arrived by floating seeds or vegetative propagules, by swimming animals, or aerially by birds, bats, or storms, all before the first humans arrival $\approx 4000$ years ago (Athens and Ward, 2004). Cycas micronesica K.D. Hill (Cycadales: Cycadaceae), Guam's only native gymnosperm and a member of the $C$. rumphii species complex, likely arrived by floating seeds. C. micronesica is also found on Rota, the island just north of Guam within the Mariana Islands, and on Yap and Palau within the western Caroline Islands (Hill, 1994). C. micronesica is an important local species since it aids recruitment and growth of other plants by adding nitrogen to the soil through the nitrogen-fixing symbiotic cyanobacteria that inhabit its coralloid roots. Many of Guam's other native plants are common on islands and coastal mainlands at tropical latitudes and are important for horticulture and landscaping.

Guam, $48 \mathrm{~km}$ long $\times 19 \mathrm{~km}$ wide at a latitude of $13.5^{\circ} \mathrm{N}$ in the western Pacific Ocean, lies within the trade wind zone where the dry season winds are typically a constant ENE with a velocity of $14-25 \mathrm{~km} \cdot \mathrm{h}^{-1}$ (Lander, 1994). One historical note that reflects on the constancy of the trade winds is that Ferdinand Magellan, who initiated the first successful naval voyage around the globe, inadvertently led his ships to the European awareness of Guam (Rogers, 2011) by sailing in the northern trade wind latitudes. C. micronesica and other native tree and shrub species inhabit coastal and littoral areas to mountain tops. Across these areas, plants experience dramatically different wind exposures that affect the pollen movement between trees or flowers within a plant's canopy or from pollen trees to ovulate trees of dioecious species such as $C$. micronesica. Wind characteristics are especially important for both anemophilous and ambophilous species.

Until $\approx 2005, C$. micronesica was the most dominant tree species in native forests of Guam on both volcanic and limestone soils (Donnegan et al., 2004). However, now it is classified as endangered by International Union for Conservation of Nature (Marler et al., 2010), due primarily to damage by invasive cycad specific pests, the scale Aulacaspis yasumatsui Takagi (Hemiptera: Diaspididae) (Marler and Muniappan, 2006), and the cycad blue butterfly, Chilades pandava 
Horsfield (Lepidoptera: Lycaenidae) (Moore et al., 2005). Surveys indicate $\approx 90 \%$ mortality of adult cycads in some populations and complete seedling mortality leading to no recruitment (Marler and Lawrence, 2012). Conservation management must not only include how to deal with these pests and the protection of seedlings to increase recruitment, but also consider management of pollination and seed development. Critical to conservation planning is how pollen is vectored from a microstrobilus on a male tree to ovules on a female tree within each of the types of environments inhabited by these plants.

A related study indicated that both insects and wind vector pollen in C. micronesica (Terry et al., 2009), but identified the need for more detailed tests to help elucidate their individual contributions. The objective of this study was to examine the pollen drift potential of $C$. micronesica. We determined the pollen settling velocity, measured wind velocities in different Guam habitats, and then used a simple mathematical model to predict the potential horizontal distance of pollen flow in each habitat. We then compared results for $C$. miconesica's pollen to those of entomophilous cycads and several native zoophilous angiosperms to ascertain whether there are any correlations between the potential mobility of pollen and pollination mode. We also compared our results, which included both fresh and treated (dried and frozen) pollen, to that of Hall and Walter (2011), who also examined pollen settling velocity of several cycads, including $C$. micronesica, but used only dried and stored pollen.

\section{Materials and Methods}

Plant species. We collected pollen from C. micronesica and from four Zamia cycad species (Zamiaceae), native to the Americas, grown at the University of Guam germplasm collection. Zamia have specialist beetles as pollinators (Stevenson et al., 1998; Tang, 2004). We also collected pollen from six tropical Guam native angiosperms that are popular horticultural and landscaping plants. These angiosperms have bisexual flowers except for Cocos nucifera which is monoecious. All species are zoophilous, or are assumed zoophilous based on floral visitors, including birds, bats, bees, beetles, butterflies, or hawk moths (Azmi et al., 2012; Hedström, 1986; Lughadha and Proenca, 1996; McClatchey, 2003; Motley et al., 2005; Razafimandimbison et al., 2012; Woodell, 1979). We selected angiosperm species whose pollen grains are monads, having one grain as the smallest unit, but they vary in size, shape, and surface texture (Fig. 1).

Pollen collection and preparation. We examined the settling velocities of both fresh and treated $C$. micronesica pollen. For treated

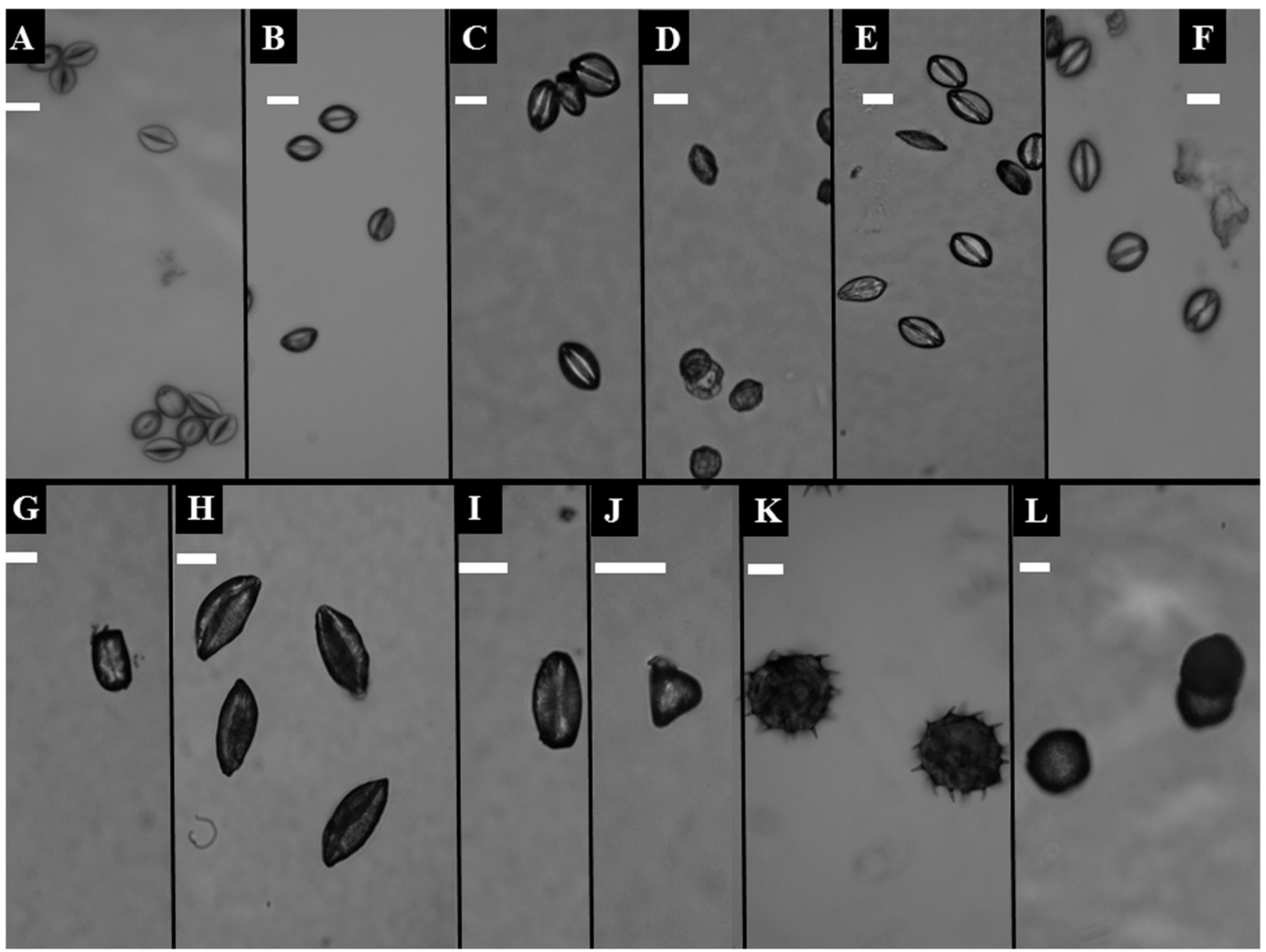

Fig. 1. Pollen images of the following species and the surface morphology: (A) Fresh and (B) treated (dried and frozen) Cycas micronesica K. D. Hill (Cycadaceae), reticulate; (C) Zamia sp. Jamaica (Zamiaceae), foveolate; (D) Z. furfuracea L.f. in Aiton, foveolate; (E) Z. integrifolia L.f., foveolate; (F) Z. herrerae S.Calderón and Standl., foveolate; (G) Bikkia tetrandra (L.f.) A. Rich. (Rubiaceae), perforate; (H) Cocos nucifera L. (Arecaceae), granulate; (I) Cordia subcordata Lam. (Boraginaceae), reticulate; (J) Eugenia reinwardtiana; (Blume) DC, (Myrtaceae), granulate, scabrate; (K) Hibiscus tiliaceus L. (Malvaceae), $\approx 18 \mu$ spines; (L) Morinda citrifolia L. (Rubiacae), reticulate. Scale bar $=20 \mu \mathrm{m}$, except $H$. tiliaceus $=50 \mu \mathrm{m}$. Grain shapes range from oblate (E. reinwardtiana) to elliptical to subspheroidal/spheroidal. Species have monoporate pore morphology except tricolporate for $B$. tetrandra, C. subcordata, and E. reinwardtiana and polyporate for H. tiliaceus. Except for size measurements done directly, information is from Dehgan and Dehgan (1988) for cycads and from Australian National University, http://apsa.anu.edu.au/ for angiosperms. 
pollen, we followed a standard procedure used for storing cycad pollen for later hand pollinations (Tang, 1985). Each microstrobilus was harvested on its first day of dehiscence and was protected from wind and rain. Pollen was collected daily over the 3 to $4 \mathrm{~d}$ dehiscence period. Each day's pollen harvest was passed through a $200-\mu \mathrm{m}$ mesh filter to remove sporangia particles and dried over Drierite $^{\circledR}$ (W.A. Hammond Drierite Company, Xenia, $\mathrm{OH}$ ) desiccant for $72 \mathrm{~h}$. This period was adequate to reduce weight loss to less than $0.2 \%$ between daily measurements, a requirement to maintain the pollen's viability after freezing (Tang, 1985). Pollen was stored at $15^{\circ} \mathrm{C}$. We recorded several measurements of the microstrobili including size and total pollen volume.

Fresh C. micronesica pollen was collected from a harvested microstrobilus that was stored overnight inside a laboratory at $\approx 23{ }^{\circ} \mathrm{C}$. Pollen was not filtered but large pieces of debris were removed and then pollen was tested the same day. To collect fresh pollen from the Zamia cycads, we tapped pollen into a paper bag, which was kept in a cooler until the pollen was tested that day. Flowers of angiosperms were placed in a paper bag and then kept cold in a cooler or refrigerator. The only angiosperm pollen tested as treated (dried and then frozen) was that of $C$. nucifera because the sticky fresh pollen was difficult to test.

Axial lengths and widths (or diameter for circular pollen) of pollen grains were measured at $40 \times$ magnification (Nikon Eclipse80i compound light microscope; Nikon Instruments Inc., Melville, NY). In addition, the diameter of $C$. micronesica micropyles and the area surrounding the micropyle (the raised area plus depression around the raised area see Fig. 2) of receptive ovules from the inside, middle, and outside whorls of megasporophylls were measured with a micro ruler $(0.1 \mathrm{~mm}$ resolution; TDI International Inc., Tucson, AZ) under a dissecting microscope (Nikon SMZ1500, Nikon Instruments Inc.).

Wind measurements in different Guam habitats. We selected different habitats where these plants are common and that represent the range of potential wind exposures on Guam. The deepest understory site was at Mangilao, an east coast cycad habitat on the side of a karst cliff that reaches $\approx 140 \mathrm{~m}$ above sea level (ASL). The specific site is on a limestone bench $\approx 73 \mathrm{~m}$ ASL characterized by a thick native forest canopy with $85 \%$ to $100 \%$ canopy cover over the cycad trees and other native plants in the understory. The Ritidian site is on the northwestern side of Guam and is shielded from direct trade winds by $180 \mathrm{~m}$ high cliffs to the northeast. We measured winds at several locations within this forested region that represent a range of settings including: a) above a male cycad tree in an open area with no other trees or obstructions within $5 \mathrm{~m}$; b) in an understory area; and c) and d) above female cycad trees in two different settings. The Ija site was located in the Ajayan River valley in southern Guam. It represents forested riparian ravines common in southern Guam where cycads and other native trees and shrubs grow midway along steep canyon walls and adjacent to the river. Wind information was collected at the ravine bottom $\approx 60 \mathrm{~m}$ below the adjacent grass dominated plains. Mt. Lamlam is Guam's highest peak, $\approx 400 \mathrm{~m} \mathrm{ASL}$, located in the southern highlands. This site was selected because of the

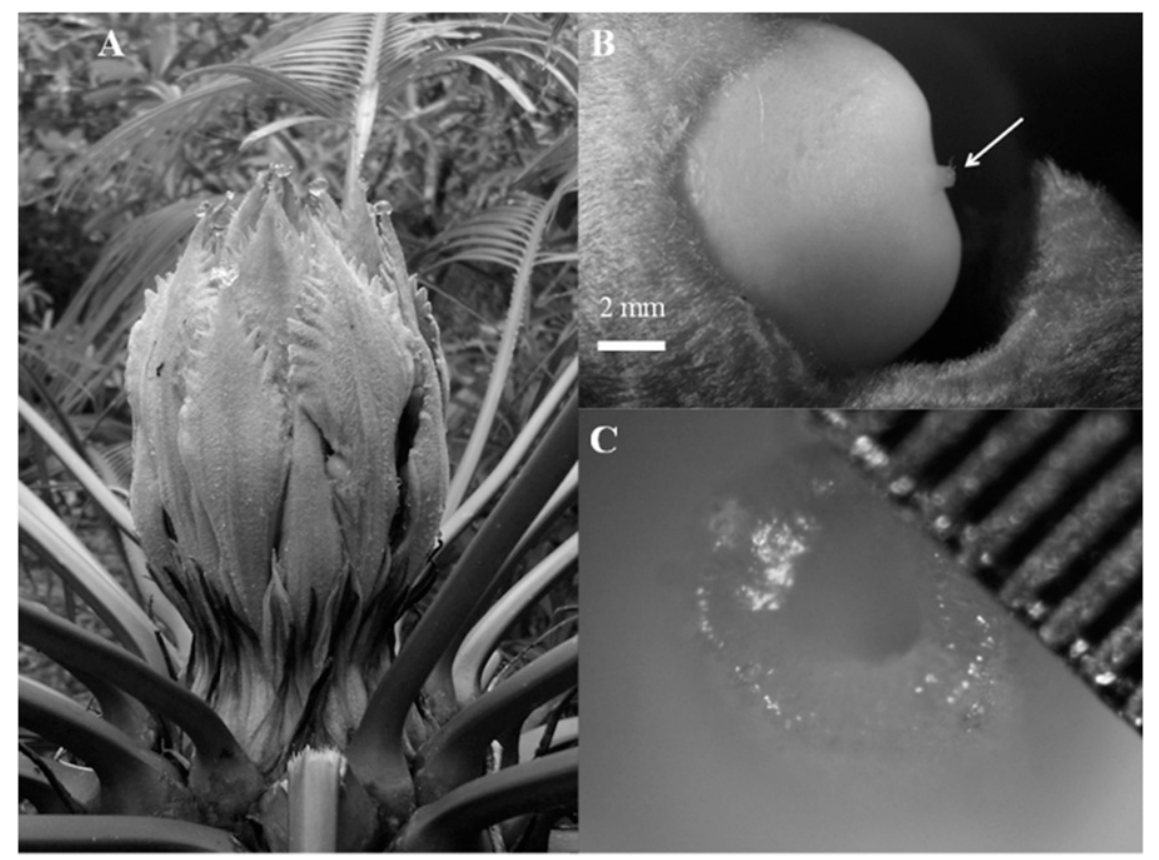

Fig. 2. Female reproductive structures of Cycas micronesica including: (A) whorl of megasporophylls during receptive period, $(\mathbf{B})$ receptive ovule with arrow pointing to micropyle, $(\mathbf{C})$ micropylar tip of a receptive ovule viewing down the micropylar canal, one division $=0.1 \mathrm{~mm}$. presence of two nearby cycad habitats, an understory site of mixed forest species and an open site with cycad trees as the dominant emergent species. Finally, we included two sites within the University of Guam Yigo Agricultural Experimental Station, an open grassland and a forested understory site.

Wind direction and velocity were recorded at each site using two or three Kestrel ${ }^{\circledR} 4500$ Pocket Weather Systems (Nielsen-Kellerman, Boothwyn, PA). Data were collected between July 2011 and the end of May 2012, plus some from a period between late June and early July 2010. At each site, we placed a Kestrel ${ }^{\circledR}$ system either above a cycad tree that was 3 to $3.5 \mathrm{~m}$ tall, or on a post at $3 \mathrm{~m}$ height, which is a common height for adult $C$. micronesica trees (Niklas and Marler, 2008). We obtained data from all sites over 2-3 different days, at 1-min sample intervals over a 5 -h period ( $\approx 1000$ to $1500 \mathrm{HR})$, except for the two Mt. Lamlam sites, where wind patterns were measured over $\approx 1$ month $(21$ Apr.-23 May 2012) at 5-min sample intervals. In addition, within the Ritidian area, we recorded wind measurements above two female trees and one male tree, at 5-min intervals over 1 week at each female tree and over 2 weeks at the male tree. The Kestrel ${ }^{\circledR}$ systems were calibrated with each other and with a Davis Vantage Pro2 ${ }^{\mathrm{TM}}$ (Davis Instruments, Hayward, CA) weather station at the University of Guam and one at the University's Yigo Agricultural Experimental Station field site occasionally throughout the year of testing, and after every change of batteries.

In addition, we downloaded data (www. wunderground.com) from different island weather stations, one located in Ipan (Davis Vantage Pro2 Plus), an east coast open area with direct exposure to trade winds, and another at Perezville (Davis Vantage Pro Plus) near Guam Memorial Hospital, as well as a Davis Vantage Pro system at Yigo. Data from these island regional sites and at Yigo were used to compare with wind patterns at other sites and served to confirm that our measured wind direction and velocities during each period were typical for Guam.

Settling velocity. The theoretical distance a particle (e.g., pollen grain or clump of grains) can travel by wind is proportional to a constant horizontal wind velocity (assuming no vertical component) and inversely proportional to the settling velocity of the particle (Aylor et al., 2003). The horizontal air velocity transports a particle away from its source, and a particle's settling velocity is the terminal velocity at which the particle falls through a column of still air (Aylor, 2002). These measurements determine the theoretical amount of time the particle will be airborne before landing if there is no significant vertical air velocity or turbulence.

The determination of the settling velocity of a particle is accomplished by allowing the particle to fall through air inside a tube without convective air currents and with a sufficient length, so that the particle can reach its terminal velocity and then allow accurate measurement of the velocity of the 
falling particle (Aylor, 2002). We used a square tube constructed of clear glass with a length of $1.5 \mathrm{~m}$ and inside dimensions of $2.5 \times$ $2.5 \mathrm{~cm}$. The tube was placed in a corner of a darkened laboratory with a relatively stable temperature and minimal air flow. Temperature, relative humidity, and barometric pressure (recorded by a Kestrel ${ }^{\circledR}$ system adjacent to the glass tube) were similar across all experiments $\left(22-24{ }^{\circ} \mathrm{C}, 41 \%-68 \%\right.$ relative humidity, and $995.8-1003.2 \mathrm{hPa}$ atmospheric pressure). The tube rested vertically on a stand. A fiber optic light, inserted through a $5 \mathrm{~cm}^{2}$ hole in the stand, illuminated the inside of the tube from the bottom.

For each experiment, we gathered pollen on a single hair of a fine paintbrush and then tapped pollen onto a piece of aluminum foil which covered the top of the tube. The foil prevented convective air currents from entering the tube, and a small pinhole in its center allowed pollen to pass through and enter the tube. Dislodged pollen was allowed to fall $0.2 \mathrm{~m}$ to account for acceleration of the particle to its terminal velocity. The time for pollen to fall $1.0 \mathrm{~m}$ was then measured (at a resolution of $0.01 \mathrm{~s}$ ). Double-sided tape on a microscope slide captured the pollen (single grains or clumps) at the bottom of the tube. The pollen was then examined under a compound light microscope for the presence of a single grain or a clump of grains. Clumps were defined as two or more pollen grains separated by less than two times the diameter of a single grain. The number of grains that comprised the clump was recorded. The tube was cleaned periodically by rinsing the interior and exterior with deionized water. The interior was dried by pulling a paper towel tied to a string through the tube several times, all in the same direction. The tube was then left to continue drying in the air.

When pollen is transported by wind, the concentration rapidly decreases with increased distance from its source due to dispersion both vertically and horizontally (Aylor et al., 2003). Knowing the horizontal wind velocity and the settling velocity of a pollen grain or clump of grains, one can determine the theoretical distance that the wind can transport the particle downwind before it falls to a specified height below the release point. For each species, we calculated the distance pollen can be transported by wind in each habitat using Eq. [1], where D is the distance traveled $(\mathrm{m}), h$ is the height of release $(\mathrm{m})$ above a potential landing site, $V_{\mathrm{w}}$ is the wind velocity $\left(\mathrm{m} \cdot \mathrm{s}^{-1}\right)$, and $V_{\mathrm{s}}$ is the particle's settling velocity $\left(\mathrm{m} \cdot \mathrm{s}^{-1}\right)$. We used the mean wind velocity at each site and predicted the horizontal distance either a single grain or an average pollen clump would move downwind before falling either 1 or $2 \mathrm{~m}$ below its source.

$$
\mathrm{D}=\left(h \cdot V_{w}\right) / V_{s}
$$

Statistical analysis. Mean wind direction and velocity at each site were calculated using Oriana $\subseteq$ (version 4.01, Kovach Computing Services, Anglesey, UK) software. Descriptive statistics including mean wind angle, mean wind velocity, and several indicators of the circular dispersion of the wind angle were calculated. Wind velocities reported as $0 \mathrm{~m} \cdot \mathrm{s}^{-1}$ refer to velocities of $\leq 0.3$ for the Kestrel ${ }^{\circledR}$ due to its minimum wind speed threshold. For consistency, we present data from the one Kestrel ${ }^{\circledR}$ Weather System that recorded data at every habitat.

An analysis of variance (ANOVA) or nonparametric Wilcoxon Rank Sum Test was used to test for differences in settling velocities of $C$. micronesica fresh and treated pollen, or of pollen from C. micronesica and other species using Statistix@ Analytical software (version 9.1, Tallahassee, FL). To eliminate the effect of clump size when comparing one species with another or treated vs. fresh pollen, we only compared pollen of the same clump sizes, e.g., two grain clumps of treated vs. two grains clumps of fresh. Regressions of the effect of the number of grains per particle on settling velocity were examined for fresh and treated pollen of C. micronesica.

\section{Results}

C. micronesica strobili and pollen measurements. Microstrobili on average were about four times longer than their diameter and had ca. 500 microsporophylls (Table 1). The microsporophylls from the middle third of the microstrobili had the highest density of sporangia and those from the top third had the lowest (means of 340 and 189 sporangia per sporophyll, respectively). The mean volume of dried pollen obtained from harvested $C$. micronesica microstrobili was $14 \mathrm{~mL}$ (range 7.5 to $34 \mathrm{~mL}$ ), with a wet/ dry weight loss of $13.83 \%$ between fresh and treated pollen. Fresh $C$. micronesica pollen grains were slightly larger than the treated pollen in both axes (Table 1). The i.d. of micropyles of ovules was $56 \%$ of the o.d. (Table 1; Fig. 2), and the size of each micropyle varied little among ovules from different megasporophylls. The diameter of the raised area around the micropyle plus the surrounding depression was $\approx 2 \mathrm{~mm}$.

Pollen grain comparisons and settling velocity. All these cycads had similar pollen sizes and similar shapes, elliptical to subspher- oidal (Fig. 1). The mean size of C. micronesica pollen was in the middle of the range of all of the cycad species' pollen, $\approx 15.5 \times 21.1$ to $19 \times 28 \mu \mathrm{m}$.

All cycad species exhibited relatively low pollen settling velocities (Table 2), with means ranging from $0.73 \mathrm{~cm} \cdot \mathrm{s}^{-1}$ for Zamia furfuracea to $1.29 \mathrm{~cm} \cdot \mathrm{s}^{-1}$ for Zamia sp. Jamaica. The mean value of $C$. micronesica's pollen was near the midpoint of this range. Whether the pollen settling velocity of a Zamia species was significantly different from that of $C$. micronesica depended on the species and whether it was a single grain or two-grain clump. Considerable overlap occurred in pollen settling velocity values of each pollen category (single or clumps) between the Zamia species and $C$. micronesica.

In comparisons of fresh and treated $C$. micronesica single pollen grains, treated pollen exhibited a slightly faster mean settling velocity (Table 2), although the mean value of the treated pollen was only 0.09 $\mathrm{cm} \cdot \mathrm{s}^{-1}$ faster than that of fresh pollen grain, and the fresh pollen settling velocity values overlapped those of the treated pollen (Fig. 3). The treated two-grain clumps also exhibited a faster settling velocity than the fresh two-grain clumps. Regression models of the effect of the numbers of grains per particle on particle settling velocity were calculated for both treated and fresh pollen clumps, but only with clumps up to seven grains. There were only a few clumps with more than seven grains. There was no significant difference between the slopes of fresh and treated pollen regressions $\left(\mathrm{F}_{(1,152)}=1.75\right.$, $P=0.1873$, slope of $0.31, r^{2}=0.54$, for fresh vs. $0.32, r^{2}=0.75$, for treated pollen). Treated grains did exhibit a slightly higher regression elevation $\left(\mathrm{F}_{(1,153)}=3.91, P=0.0497\right.$, intercepts of 0.64 for fresh vs. 0.82 for treated pollen) (Fig. 3) suggesting that treated grains had an overall faster settling velocity than the fresh grains. There was considerable overlap in data between fresh and treated pollen in most clump size categories.

The pollen grains of the angiosperm species were larger than those of C. micronesica, 1.5 to 4 times the longest axis, except for the smaller Eugenia reinwardtiana grains

Table 1. Cycas micronesica microstrobilus, pollen, and micropyle measurements.

\begin{tabular}{lcc}
\hline Strobilus or ovule section & $\mathrm{n}$ & Mean $\pm \mathrm{SE}$ \\
\hline Microstrobili & & \\
$\quad$ Diameter $(\mathrm{cm})$ & 16 & $10.5 \pm 0.40$ \\
Length $(\mathrm{cm})$ & 16 & $40.6 \pm 2.29$ \\
$\quad$ Fresh weight $(\mathrm{g})$ & 11 & $1190 \pm 116.1$ \\
$\quad$ Microsporophylls per microstrobilus & 5 & $498 \pm 38.06$ \\
Sporangia per microsporophyll & & \\
$\quad$ Top third of microstrobilus & 3 & $189 \pm 42.67$ \\
$\quad$ Middle third of microstrobilus & 3 & $342 \pm 26.72$ \\
$\quad$ Bottom third of microstrobilus & 3 & $276 \pm 30.19$ \\
Pollen & & \\
$\quad$ Treated, length $(\mu \mathrm{m})$ & 90 & $25.3 \pm 0.48$ \\
Treated, width $(\mu \mathrm{m})$ & 90 & $27.7 \pm 0.18$ \\
Fresh, length $(\mu \mathrm{m})$ & 90 & $20.3 \pm 0.14$ \\
$\quad$ Fresh, width $(\mu \mathrm{m})$ & 90 & $0.31 \pm 0.01$ \\
Micropylar tip & & $0.55 \pm 0.01$ \\
$\quad$ Inside diameter $(\mathrm{mm})$ & 12 & \\
Outside diameter $(\mathrm{mm})$ & 12 &
\end{tabular}

${ }^{2}$ Length and width of pollen grain, as in Dehgan and Dehgan (1988). 
Table 2. Mean pollen settling velocity $\left(\mathrm{V}_{\mathrm{s}}\right)$ for individual grains or two-grain clumps of each species, and test results (F, ANOVA, or W, Wilcoxon Rank Sum value) comparing $\mathrm{V}_{\mathrm{s}}$ of fresh Cycas micronesica (first row) pollen to treated C. micronesica pollen and to each species' pollen.

\begin{tabular}{|c|c|c|c|c|c|c|c|}
\hline \multirow[b]{2}{*}{ Plant species ${ }^{z}$} & \multicolumn{3}{|c|}{ Single grain } & \multicolumn{3}{|c|}{ Two-grain clump } & \multirow{2}{*}{$\begin{array}{c}\text { No./clump } \\
\text { Mean no. per } \\
\text { clump (maximum) }\end{array}$} \\
\hline & $\begin{array}{c}\text { Mean } V_{\mathrm{s}} \\
\left(\mathrm{cm} \cdot \mathrm{s}^{-1}\right) \pm \mathrm{SE}\end{array}$ & $\mathrm{n}$ & $\mathrm{F}$ or $\mathrm{W}$ value ${ }^{\mathrm{y}}$ & $\begin{array}{c}\text { Mean } V_{\mathrm{s}} \\
\left(\mathrm{cm} \cdot \mathrm{s}^{-1}\right) \pm \mathrm{SE}\end{array}$ & $\mathrm{n}$ & $\begin{array}{l}\text { F or W } \\
\text { value }^{y}\end{array}$ & \\
\hline C. micronesica & $0.98 \pm 0.06$ & 37 & - & $1.89 \pm 0.14$ & 59 & - & $4.2(22)$ \\
\hline Z. furfuracea & $0.73 \pm 0.06$ & 5 & $1.4 \mathrm{NS}$ & $0.74 \pm 0.08$ & 15 & $3.6 * * *$ & $4.3(14)$ \\
\hline Z. integrifolia & $1.01 \pm 0.04$ & 11 & $1.9 \mathrm{NS}$ & $1.57 \pm 0.18$ & 9 & $1.7 \mathrm{NS}$ & $2.4(4)$ \\
\hline Z. herrerae & $1.19 \pm 0.10$ & 9 & $2.7 * *$ & $2.22 \pm 0.26$ & 11 & $0.4 \mathrm{NS}$ & $4.1(8)$ \\
\hline Cordia subcordata & $5.18 \pm 0.15$ & 5 & $4.8^{* * *}$ & $7.24 \pm 0.60$ & 5 & NA & $2.2(3)$ \\
\hline Eugenia reinwardtiana & $0.72 \pm 0.01$ & 10 & $4.1 * * *$ & $0.96 \pm 0.08$ & 10 & $2.4 *$ & $2.5(3)$ \\
\hline Hibiscus tiliaceus & $26.64 \pm 0.6$ & 9 & $5.3 * * *$ & $39.15 \pm 2.6$ & 4 & NA & $2.3(3)$ \\
\hline Morinda citrifolia & $3.83 \pm 0.14$ & 18 & $6.1 * * *$ & 7.12 & 1 & NA & $3(3)$ \\
\hline
\end{tabular}

${ }^{2}$ Zamia species are native only to the Americas, all other species are native to Guam. All species are tested with fresh pollen except where indicated as Trted (treated $=$ dried and frozen).

${ }^{y}$ Results of ANOVA, F value, or Wilcoxon Rank Sum, W value, and significance; $\mathrm{df} \geq 24$; $\mathrm{NS},{ }^{*}, * *, * * *$ Nonsignificant or significant at $P \leq 0.05,0.01$, or 0.001 , respectively.

${ }^{x}$ Mean no. per clump (maximum), number of grains per particle for particles with $\geq 2$ grains. In C. micronesica, fresh pollen had clumps up to 22 grains but only 11 grains in treated pollen. Means include only those up to 11 grains. Bikkia tetrandra pollen landed as single grains only.

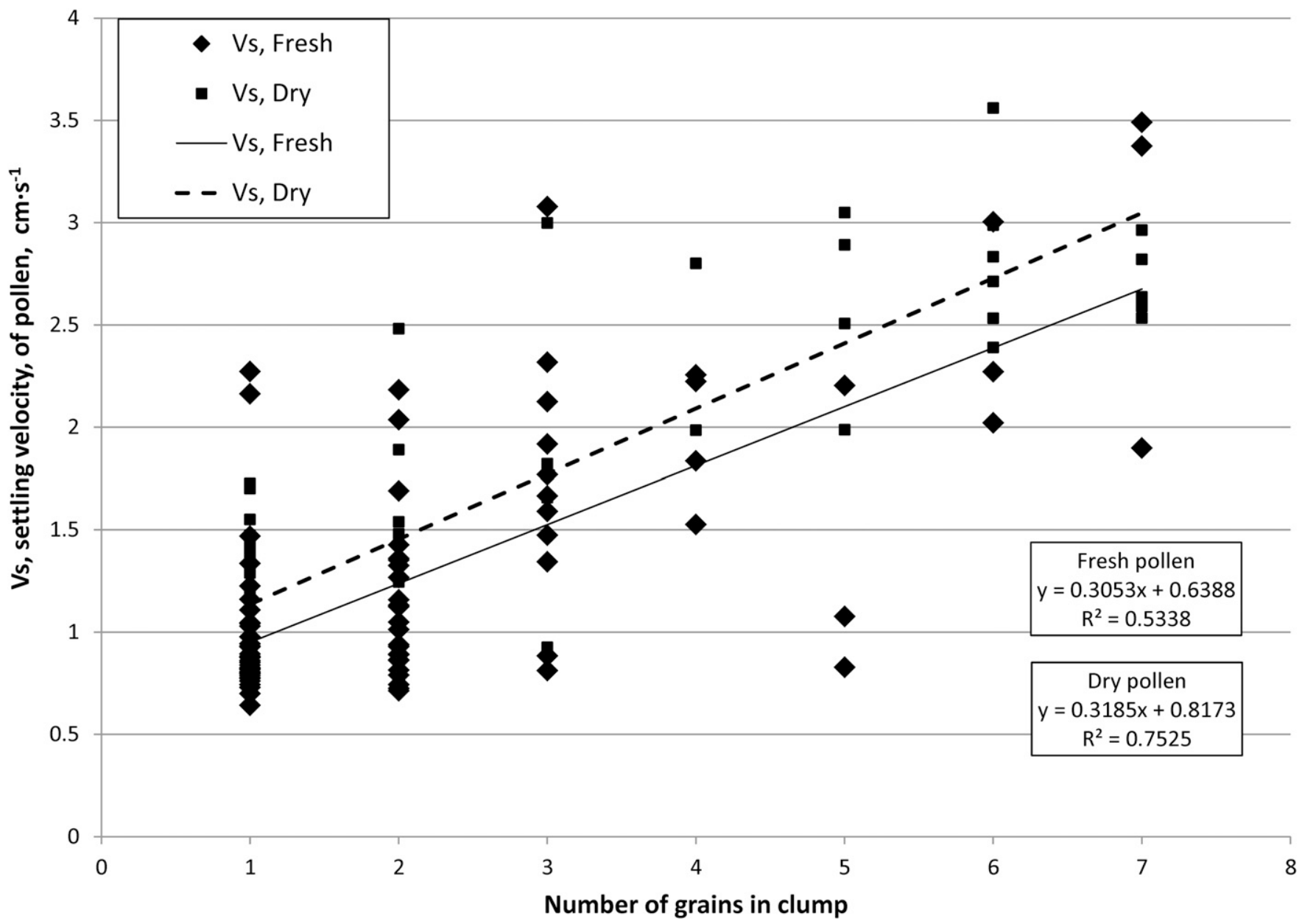

Fig. 3. Regression models of the effect of the number of grains per particle on pollen settling velocity for both fresh and treated Cycas micronesica pollen samples ranging from particle sizes of single grains to clumps with seven grains.

(Figs. 1 and 4). All species with larger pollen grains exhibited faster pollen settling velocities, 3 to 26 times $C$. micronesica pollen's mean value (Table 2), and none of the individual values overlapped with any of the values of $C$. micronesica's pollen. The mean settling velocity of pollen of $E$. reinwardtiana was significantly slower than that of fresh C. micronesica pollen (either single grains or two-grain clumps, Table 2), but there was no significant difference for threegrain clumps $\left(\mathrm{F}_{(1,14)}=3.85, P=0.0698\right.$, ANOVA). The pollen of $C$. nucifera exhibited the highest variability in settling velocity (SE, Table 2; Fig. 4) of all species and had the highest $\mathrm{CV}(0.30$, compared with a range of 0.04 to 0.25 for all other species). This variability may be due to the presence of two grain shapes, one type is oblate elliptical and the other is spherical (Nair and Sharma, 1963). As the size of the pollen grain 
increases there is a significant increase in the settling velocity across the wide range of pollen sizes tested (Fig. 4).

Pollen drift distances. Cycad habitats differed dramatically in their wind velocity (Table 3). Measurements at each habitat, except at Ipan, were collected on different days, so data among sites are not directly comparable. However, wind measurements were collected at Ipan on all days, and wind velocity and direction at Ipan across those sample periods were typical trade winds (Hamada et al., 2015) suggesting that differences among sites reflect the effects of the habitat. The Perezville and Yigo regional weather stations failed to record during all days, so data are not presented, but they generally agreed with that of Ipan. As expected, the open east coastal habitat at Ipan exhibited the greatest wind velocity with a tight mean directional component (Table 3, $r$ values) with an ENE to north northeast (NNE) direction, with winds at the two other open areas at Yigo and Mt. Lamlam exhibiting a more easterly direction. All understory habitats exhibited much lower wind velocities and were generally more variable in wind direction. The sites with the lowest wind velocities were at Mangilao, the site that had the highest canopy cover, and at Ritidian site $\mathrm{D}$ that had numerous obstructions near the plant even though there was less canopy cover overhead than at the Mangilao site. More than $89 \%$ of the Ritidian and more than $99 \%$ of the Mangilao wind samples recorded no wind velocity.

We calculated the theoretical distance an individual grain or clump of grains could travel in each habitat before it would fall 1 or $2 \mathrm{~m}$ below the pollen source height by using Eq. [1] with values of wind velocity for each habitat (Table 3) and each species' mean pollen settling velocity for one grain or for the average clump size (Table 2). For $C$. micronesica, the theoretical distances a single grain $\left(V_{\mathrm{s}}=1 \mathrm{~cm} \cdot \mathrm{s}^{-1}\right)$ or a five-grain clump $\left(V_{\mathrm{s}}=2.25 \mathrm{~cm} \cdot \mathrm{s}^{-1}\right)$ can travel before it falls 1 or $2 \mathrm{~m}$ (e.g., settles onto megasporophylls 1 or $2 \mathrm{~m}$ below) ranged from $<1 \mathrm{~m}$ in dense understory areas to $>200 \mathrm{~m}$ in open areas (Figs. 5 and 6). At the Mt. Lamlam exposed cycad habitat, for example, the mean wind velocity of $2.3 \mathrm{~m} \cdot \mathrm{s}^{-1}$ could carry a pollen grain $\approx 235 \mathrm{~m}$ from a microstrobilus before falling $1 \mathrm{~m}$ in elevation; for a five-grain clump of pollen the distance was $\approx 120 \mathrm{~m}$. At all but the three sites with the lowest mean wind velocities, wind could transport pollen, either single grains or five-grain clumps, over $20 \mathrm{~m}$ before settling on a surface $1 \mathrm{~m}$ below its source (Fig. 6).

At deep understory sites or sites with numerous surrounding trees or obstructions,

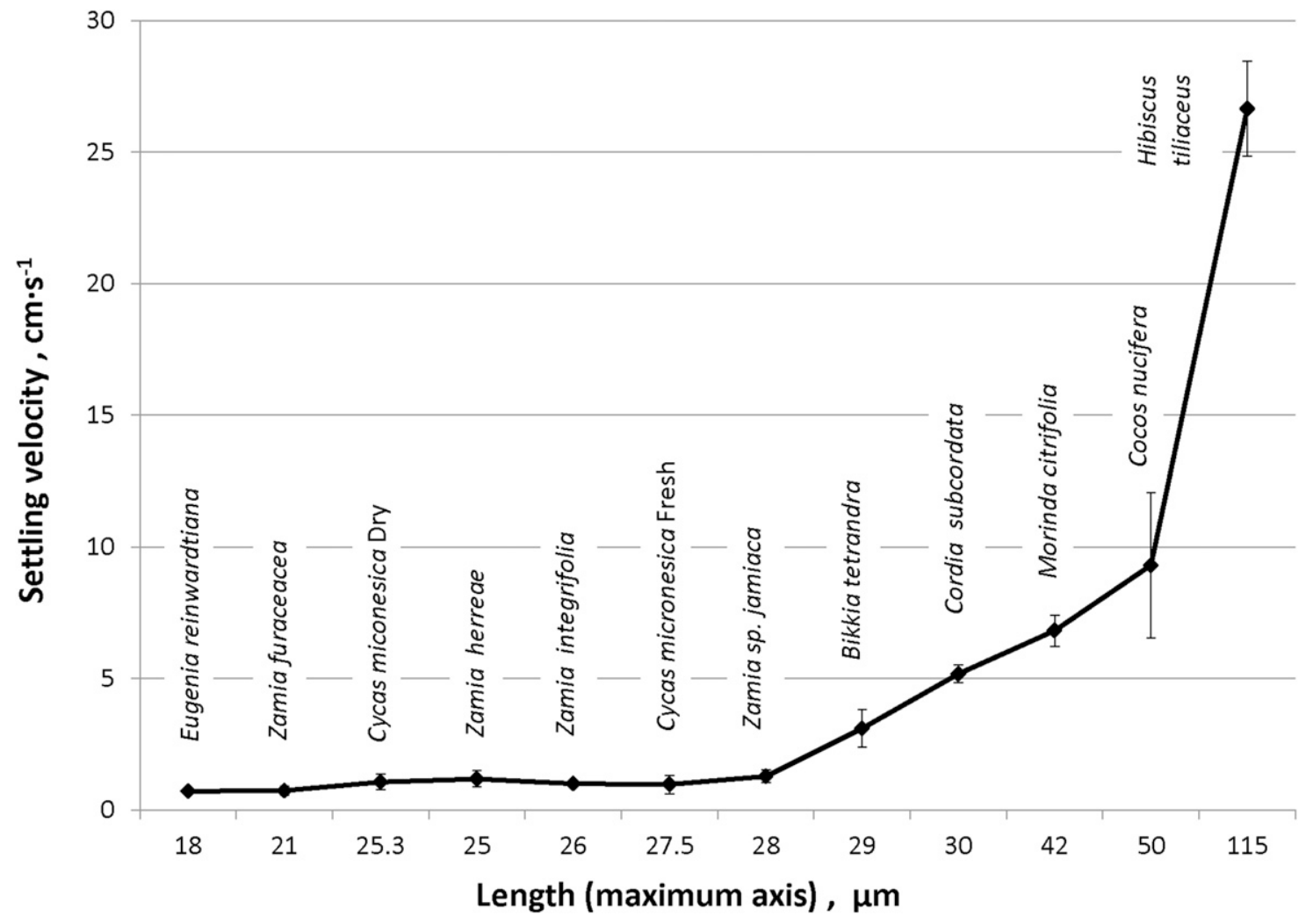

Fig. 4. The relationship between the pollen settling velocity of single pollen grains $( \pm \mathrm{SE})$ and the mean size of the pollen for several cycad and angiosperm species over a wide range of pollen sizes, where the length of maximum axis of each species' pollen grain is a proxy for pollen size.

Table 3. Mean and maximum wind velocities, mean wind direction vector, and associated $r$ (strength of the wind direction vector, scaled $0-1$ ) at each Guam site.

\begin{tabular}{|c|c|c|c|c|c|c|c|c|c|c|}
\hline Site & Location & $\begin{array}{c}\text { North latitude, } \\
\text { decimal }\left({ }^{\circ}\right)\end{array}$ & $\begin{array}{l}\text { East longitude, } \\
\text { decimal }\left({ }^{\circ}\right)\end{array}$ & $\begin{array}{l}\text { Elevation } \\
(\mathrm{m})\end{array}$ & $\begin{array}{c}\text { Canopy } \\
\text { cover }(\%)\end{array}$ & $\begin{array}{l}\text { Mean wind } \\
\left(\mathrm{m} \cdot \mathrm{s}^{-1}\right)\end{array}$ & $\begin{array}{l}\text { Max. wind } \\
\left(\mathrm{m} \cdot \mathrm{s}^{-1}\right)\end{array}$ & $\begin{array}{l}\%^{\mathrm{z}} \text { wind } \\
0 \mathrm{~m} \cdot \mathrm{s}^{-1}\end{array}$ & $\begin{array}{l}\text { Direction } \\
\text { vector }\left({ }^{\circ}\right)\end{array}$ & $\begin{array}{c}r \text { of } \\
\text { vector }\end{array}$ \\
\hline Yigo field & North central plains & 13.53167 & 144.87178 & 148 & 0 & 3.3 & 8.3 & 4.1 & 80 & 0.95 \\
\hline Mt. Lamlam field & South mountain plains & 13.33578 & 144.67053 & 400 & 0 & 2.3 & 7.7 & 6.5 & 85 & 0.91 \\
\hline Ritidian A & Northwest forest & 13.64392 & 144.85639 & 96 & 0 & 0.7 & 4.3 & 26 & 7 & 0.56 \\
\hline Yigo forest & North central forest & 13.53031 & 144.87092 & 142 & 73 & 0.55 & 3 & 31 & 73 & 0.8 \\
\hline Ritidian B & Northwest forest & 13.64578 & 144.85667 & 84 & 84 & 0.45 & 2.4 & 41 & 73 & 0.9 \\
\hline Mangilao & East coast plateau & 13.46569 & 144.84931 & 73 & 94 & 0.055 & 0.8 & 89.4 & 345 & 0.73 \\
\hline Ritidian D & Northwest forest & 13.64511 & 144.85894 & 98 & 80 & 0.01 & 0.4 & 99.8 & 337 & 0.93 \\
\hline
\end{tabular}

zo wind, $0 \mathrm{~m} \cdot \mathrm{s}^{-1}=$ the percentage of the $1 \mathrm{~min}$ or $5 \mathrm{~min}$ wind samples that recorded no wind movement, $0 \mathrm{~m} \cdot \mathrm{s}^{-1}$. 


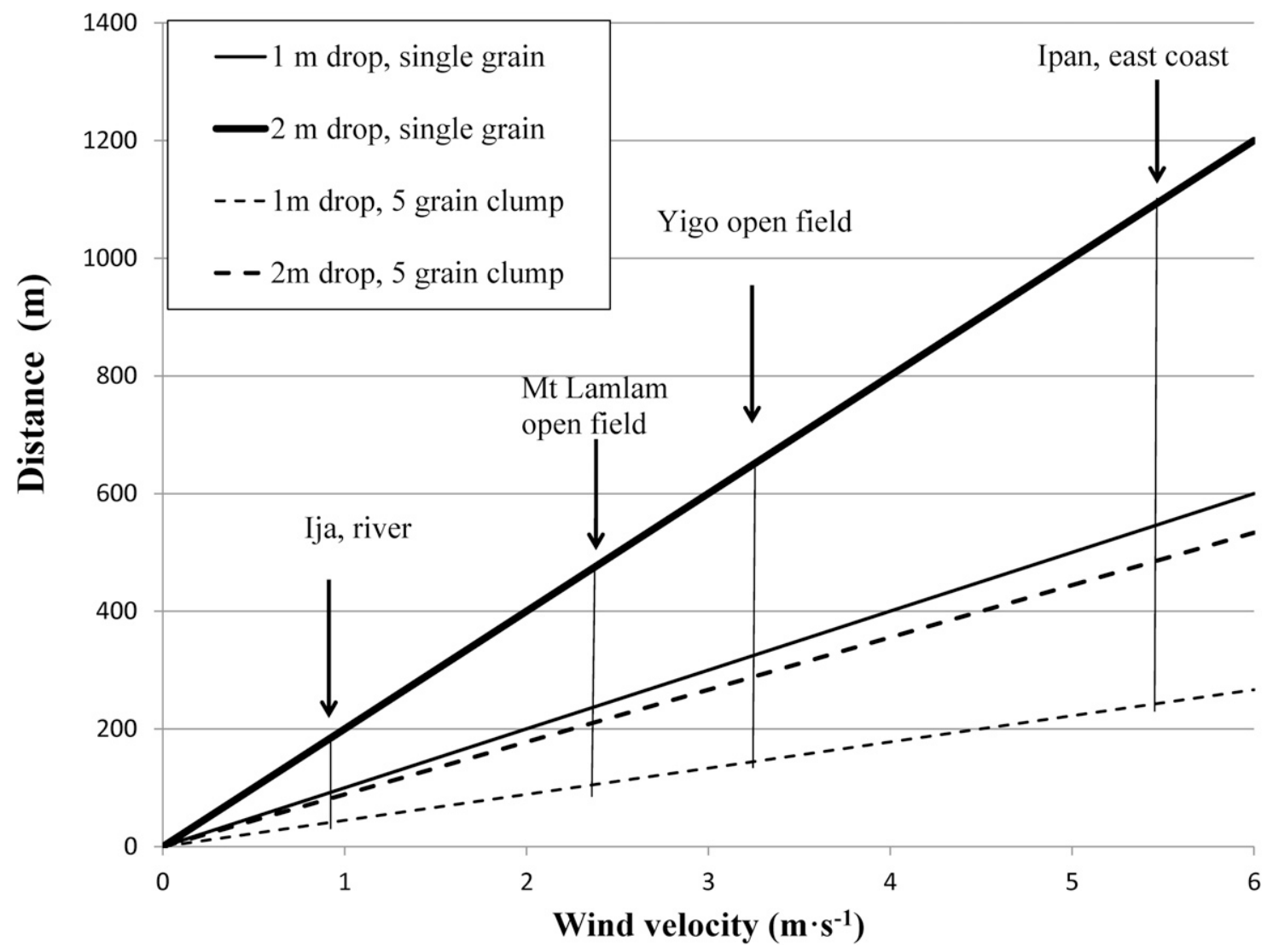

Fig. 5. Application of Eq. [1] illustrating the theoretical distance an individual Cycas micronesica pollen grain or a five-grain clump (with mean settling velocities of $1 \mathrm{~cm} \cdot \mathrm{s}^{-1}$ and $2.25 \mathrm{~cm} \cdot \mathrm{s}^{-1}$, respectively) can travel before settling on a surface (e.g., megasporophylls) 1 or $2 \mathrm{~m}$ lower (indicated as 1 or $2 \mathrm{~m}$ drop) than the pollen source (microstrobilus) and subjected to constant horizontal wind velocities. Arrows representing the mean wind velocity $\left(0 \mathrm{~m} \cdot \mathrm{s}^{-1}\right.$ wind velocities included) measured at each site.

such as Mangilao or Ritidian D, we predicted that wind could transport a single grain; $\approx 5$ or $1 \mathrm{~m}$, respectively, for a $1 \mathrm{~m}$ decrease in height. Because $>89 \%$ of the wind samples at Mangilao and Ritidian D recorded no air movement, most of the time, air currents would not be sufficient to carry pollen far from the plant, or indeed even out of the strobilus.

Within the angiosperms, E. reinwardtiana had the slowest pollen settling velocity, and the results were similar to those of $C$. micronesica in that wind could potentially transport its pollen tens to hundreds of meters from its source before dropping $1 \mathrm{~m}$ in most habitats, but $<1.4 \mathrm{~m}$ in the deeper understory sites. In open habitats, the predicted distances that wind could transport pollen for the other angiosperms ranged from hundreds of meters for Bikkia tetrandra but $<20 \mathrm{~m}$ for Hibiscus tiliaceus (Figs. 7 and 8). In more forested habitats, the distances ranged from $1 \mathrm{~m}$ in habitats with the least wind to $35 \mathrm{~m}$ in Yigo forest for $B$. tetrandra pollen, and from $<75$ $\mathrm{cm}$ to $\approx 5 \mathrm{~m}$ for $H$. tiliaceus.

\section{Discussion}

Implications of pollen size and pollen flow distances for wind potential as vector. There were no major differences in pollen grain size, shape, or settling velocity to suggest a different pollination system for C. micronesica from that of Zamia species that are entomophilous (Fig. 1; Table 2). The pollen size of $C$. micronesica and of each Zamia species reported here was within the size range of the entomophilous Cycas and Zamia species reported by Dehgan and Dehgan (1988): pollen sizes of Cycas species with the smallest (C. revoluta) and the largest $(C$. circinalis) grains were $15.5 \times 22.2 \mu \mathrm{m}$ and $19.6 \times 28.1 \mu \mathrm{m}$, respectively; and the range of sizes for Zamia species with the smallest and largest grains were $15.7 \times 21.1 \mu \mathrm{m}$ and $19.4 \times$ $29.1 \mu \mathrm{m}$, respectively.

On the other hand, the results on the potential distance of pollen flow in most Guam environments (ranging from $20 \mathrm{~m}$ to several hundred meters) indicate that winds are not necessarily a constraint for wind pollination effectiveness for cycads, and even for many zoophilous species with moderately large pollen grains. Distances between reproducing ovulate and pollen $C$. micronesica trees are as low as 3 and $4 \mathrm{~m}$ in natural settings (Hamada et al., 2015) and are thus well within the range of the potential distances of pollen flow. The ovulate and pollen trees are about the same height on average (Niklas and Marler, 2008). Because in most habitats wind can carry pollen a long distance before pollen drops $1 \mathrm{~m}$ in elevation, it is likely that ovulate trees even the same height as pollen trees many meters away could receive substantial pollen. However, the wind would not likely be a reliable vector for any of these plants in deep understory environments. Various other factors will affect flow of pollen including obstructions, eddy effects, boundary layers, and changes in wind direction or velocities, although mean wind direction vectors in most locations suggested a strong directional downwind component (Table 3). Notably, open habitats, but not understory areas, would be subject to solar heating and increased convective air currents that would increase pollen drift distances. We did not have the appropriate equipment to evaluate the effects of turbulent eddy covariances or other factors (Martin et al., 2009).

For all species studied herein, many other biotic factors, in addition to the pollen size, will affect whether wind would be an effective vector (Friedman and Barrett, 2009). These include total pollen production, the size of the stigma (and whether it is exerted outside the corolla) for angiosperms, and for cycads, the size of the micropyle or ovule (that are never exerted outside the megasporophylls, but those on the outer whorls of megasporophylls may be exposed to the airborne pollen), and the density of the vegetation within the canopy that may impede wind thus increasing turbulence. The 


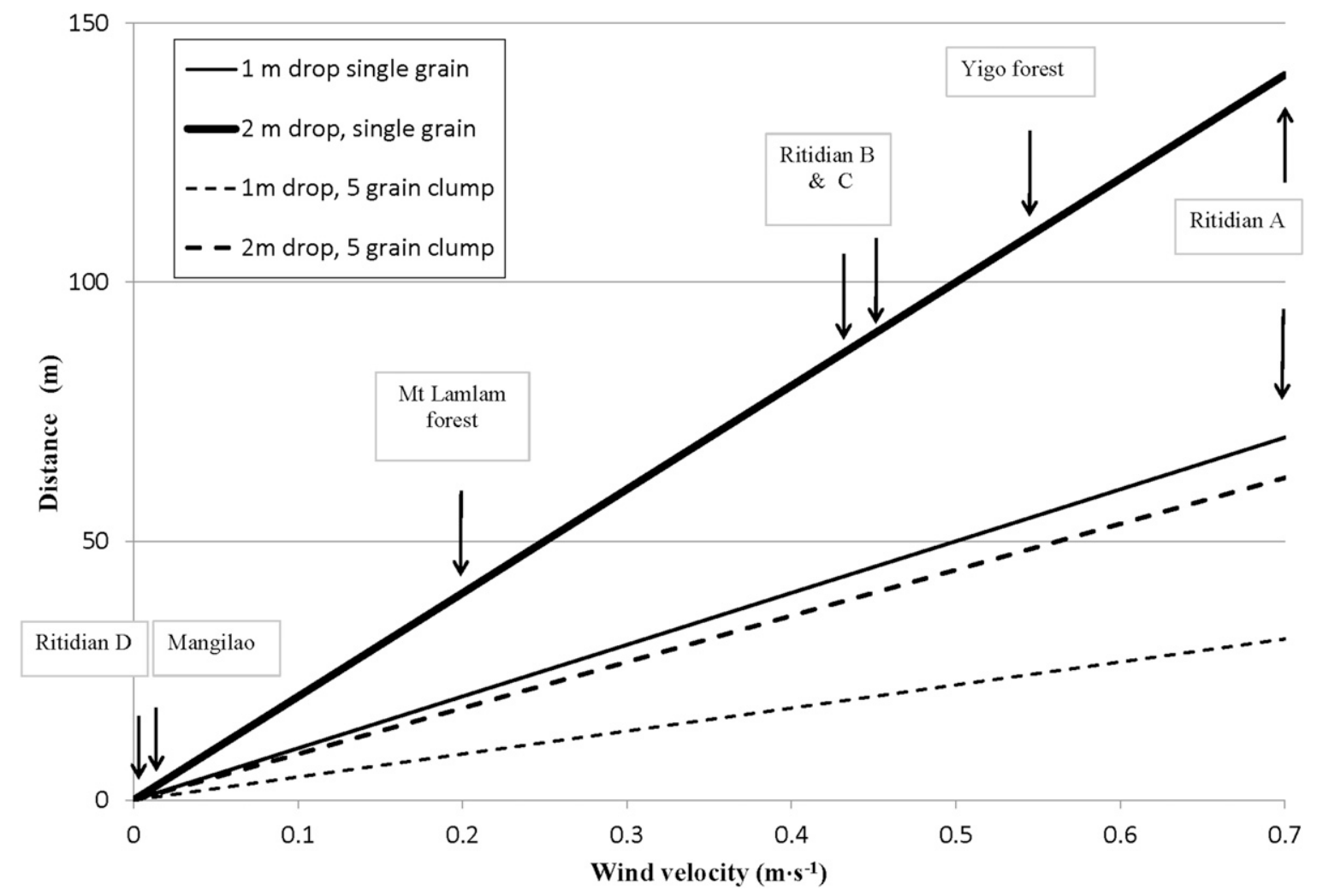

Fig. 6. Application of Eq. [1] illustrating the theoretical distance an individual Cycas micronesica pollen grain or a five-grain clump (with mean settling velocities of $1 \mathrm{~cm} \cdot \mathrm{s}^{-1}$ and $2.25 \mathrm{~cm} \cdot \mathrm{s}^{-1}$, respectively) can travel before settling on a surface (e.g., megasporophylls) 1 or $2 \mathrm{~m}$ lower (indicated as 1 or $2 \mathrm{~m}$ drop) than a pollen source (microstrobilus) and subjected to constant horizontal wind velocities. Arrows representing the mean wind velocity $\left(0 \mathrm{~m} \cdot \mathrm{s}^{-1}\right.$ wind velocities included) measured at each site.

sexual reproductive organs of many of these species are exposed to the air, but are within a dense vegetative canopy. In addition, many of these plants, such as Cordia subcordata, are tall trees that are part of the upper canopy where turbulence and canopy structure affect pollen movement.

Pollen size effects on settling velocity. Only a few studies have examined closely the role of wind in the pollination of any Cycas species, with even fewer studies of those in the C. rumphii species complex. Hall and Walter (2011) showed there was no significant difference between the settling velocities of $C$. micronesica and other island cycad pollen (from 0.7 to $0.9 \mathrm{~cm} \cdot \mathrm{s}^{-1}$ ) and the mainly insect pollinated $C$. revoluta pollen $\left(0.8 \mathrm{~cm} \cdot \mathrm{s}^{-1}\right)$. Their measurements were made using dehydrated and refrigerated pollen, which they suggested could result in underestimating the settling velocity of fresh pollen, possibly due to the dried pollen's reduced mass. That suggestion is only true on the condition that the pollen's dimensions are not altered during dehydration (Eq. [2] and Aylor, 2002).

To provide a framework for understanding differences between fresh and dried pollen, we take into account that pollen grains, being small particles falling freely at slow velocities, can be considered to be governed by Stokes' Law (Aylor 2002). When this law is used with Newton's second law of motion for a nonaccelerating body, and neglecting the small bouyant force of the air, this results in the settling velocity of

$$
\mathrm{V}_{s}=\frac{\mathrm{m} \cdot \mathrm{g}}{6 \pi \mu \mathrm{R}}
$$

Here $\mathrm{m}$ is the pollen grain's mass, $\mathrm{g}$ is the acceleration of gravity, $\mu$ is the dynamic viscosity of air, and $R$ is the radius of the particle (or its equivalent radius for nonspherical particles).To compare fresh and treated grains using Eq. [2], one must consider that drying and freezing pollen would decrease the mass due to water loss which would decrease $V_{\mathrm{s}}$, but it would also decrease the radius due to shrinkage, which would increase $V_{\mathrm{s}}$. The faster settling velocity, on average, of the treated C. micronesica pollen, therefore, is likely due to the reduction in size $(R)$ being larger than the reduction in mass during the drying procedure, yielding a larger value of $\mathrm{m} / \mathrm{R}$ in Eq. [2]. Although the grains' masses were not measured, the lengths and widths of dehydrated and frozen $C$. micronesica pollen grains were on average 2.2 and $1.6 \mu \mathrm{m}$ smaller, respectively, than their fresh counterparts (Table 2), resulting in a twodimensional area of $\approx 85 \%$ of the fresh pollen grains. See Aylor $(2002,2003)$ for further discussion of pollen density changes due to water loss in dried pollen that may also affect the settling velocity.

The theoretical effect of grain size alone across all species can be examined by replacing the grain mass in Eq. [2] by its volume $\left(\frac{4}{3} \pi R^{3}\right)$ times its density $(\rho)$, giving,

$$
\mathrm{V}_{s}=\frac{\mathrm{g} \rho R^{2}}{4.5 \mu}
$$

This explains how the settling velocity would increase with larger grains when the densities of fresh grains of different species are about the same and they have a similar shape (Fig. 4). This equation also illustrates the effect of changes in settling velocity due to clump size as in Fig. 3, since clumps of tightly packed grains are expected to have densities close to that of the individual grains.

Hall and Walter (2011) also concluded that $C$. micronesica and other 'island cycads' should be animal pollinated based on the pollen's tendency to fall as clumps as opposed to individual grains, and that settling velocity was a poor indicator of type of pollen vector. Similarly, Timerman et al. (2014), studying a large number of plants, reported that pollen of zoophilous plants tended to clump more (had a lower percentage of single pollen grains and a higher average number of pollen grains per clump) than anemophilous plants.

While our results did indicate that Cycas pollen has a tendency to clump (but also falls as single grains), the assertion that C. micronesica should be animal pollinated because of the clumping nature of cycad pollen requires re-evaluation. Firstly, pollen clumps from flowers or cones found in settling 


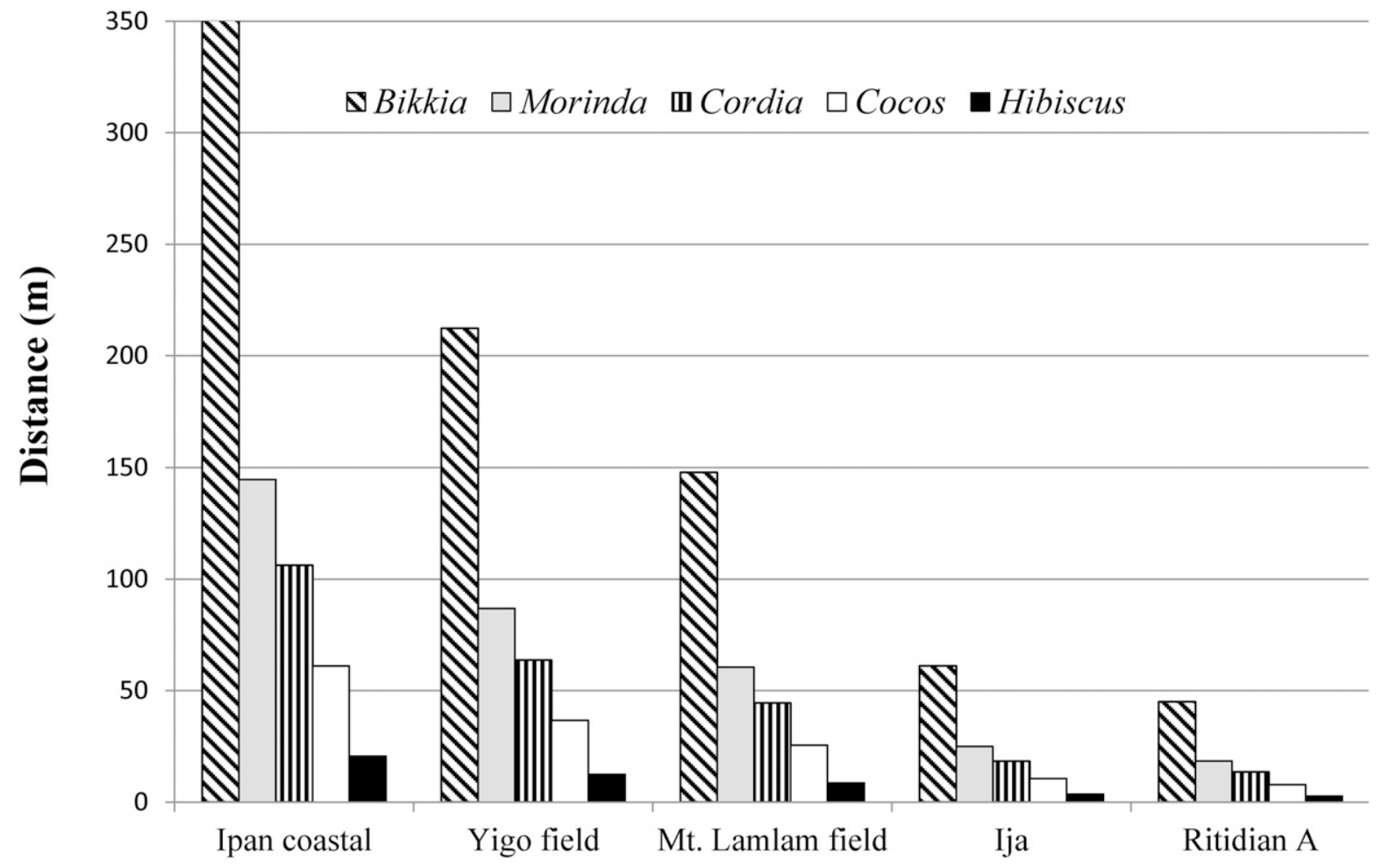

Fig. 7. Application of Eq. [1] illustrating the theoretical distance an individual pollen grain of each angiosperm species can travel in these open habitats before settling on a surface $1 \mathrm{~m}$ below the pollen source and subjected to mean constant wind velocity at each habitat (Table 3). (See Table 2 for mean settling velocities.)

velocity tests may not represent the types of clumping present after breakup of pollen clumps due to wind shear, eddies, or other disturbances after being suspended and transported by wind (Martin et al., 2009). Secondly, even though $C$. micronesica pollen landed as both individual grains and in clumps, mostly $<11$ grains per clump, in most trade wind habitats, wind is sufficient to transport clumped pollen substantial distances before it is predicted to land on a surface $1-2 \mathrm{~m}$ below. Thirdly, we also found that all cycad pollen, including those in genus Zamia that are considered strictly entomophilous, settled much slower than pollen from different animal pollinated angiosperms. Finally, in a study where $C$. micronesica pollen was captured at different distances from pollen sources in different Guam habitats, substantial pollen was captured on traps up to at least $8 \mathrm{~m}$ from the pollen source except in the deep understory habitats where pollen capture was extremely low even at $4 \mathrm{~m}$ (Hamada et al., 2015). In some open habitats, traps at 16 and $32 \mathrm{~m}$ downwind of the pollen source captured substantial pollen. In addition, pollen traps around female sporophylls within $\approx 6 \mathrm{~m}$ of pollen cones in forested areas captured substantial pollen, even when megasporophylls were taller than the pollen strobilus. Thus, even though small and light pollen may be insect vectored, that does not preclude anemophily as does very large, high density pollen grains. Also, small pollen size indicates little about the size of the pollinator. For example, some Macrozamia cycad species are effectively pollinated by both $\approx 5 \mathrm{~mm}$ long Tranes sp. weevils and 1-2 mm long Cycdothrips thrips (Terry, 2001; Terry et al., 2005 ), although their pollen loads are dramatically different.

Horticultural relevance. The species we selected for inclusion are prominently positioned in the landscape industry or possess great potential for landscaping. The cycad species in particular are used in the horticulture trade in various locations, and are represented in botanical gardens throughout the world. In regions such as Guam where $A$. yasumatsui and $C$. pandava pests have become established so that attempting to grow Cycas species may be too costly, horticulturists interested in cycad biology may focus on Zamia and other genera that are not as susceptible to those pests.

Understanding the pollination biology of these species is of crucial importance to horticulturists and curators of botanical gardens. For example, if Cycas species that are sexually compatible with $C$. micronesica are introduced to Guam's landscapes and the island's chronic trade winds are effective vectors of Cycas pollen, horticulturists should ensure that exotic species are not located near any native forests to avoid genetic contamination. In botanic gardens, most collections of cycad species are planted in close proximity, and controlled pollinations account for $100 \%$ of their pollination's effectiveness because the specialist pollinator species for entomophilous cycads are absent from these settings. If wind pollination is possible, then curators should alter the management protocols of the multi- species collections in designing plantings to avoid cross-pollination, and they should avoid collecting seed that may have been cross pollinated.

Despite the ecological, horticultural, and/or landscaping importance of the angiosperms in this study, relatively little is known about their pollination except for $C$. nucifera. Pollination of the monoecious $C$. nucifera has been studied extensively across many tropical areas with results suggesting that this species has a mixed mating strategy of primarily xenogamy (cross-pollination) with some geitenogamy (self-pollination from different flowers within same tree) (MeléndezRamírez et al., 2004). Both insects [bees, flies, and beetles appear to pollinate or at least visit flowers of both sexes (Ashburner et al., 2001; Hedström, 1986; Kevan, 1993; MeléndezRamírez et al., 2004)] and wind play a role in both mating strategies, but similar to our results, the contribution of wind depends on location. In the Maldives where there are consistent winds, Kevan (1993) reported that wind is about equal to that of insects as a pollen vector. In contrast, where winds are light, wind only accounted for about $4 \%$ of the pollination in inland Papua New Guinea (Ashburner et al., 2001) and about $10 \%$ of the xenogamous pollination on the Yucatan Peninsula (Meléndez-Ramírez et al., 2004). For the other angiosperms, they are only assumed to be animal pollinated based on either surveys of insect visitors or on studies of related species or genera, but not on pollinator exclusion/ inclusion studies (Azmi et al., 2012; Lughadha and Proenca, 1996; McClatchey, 


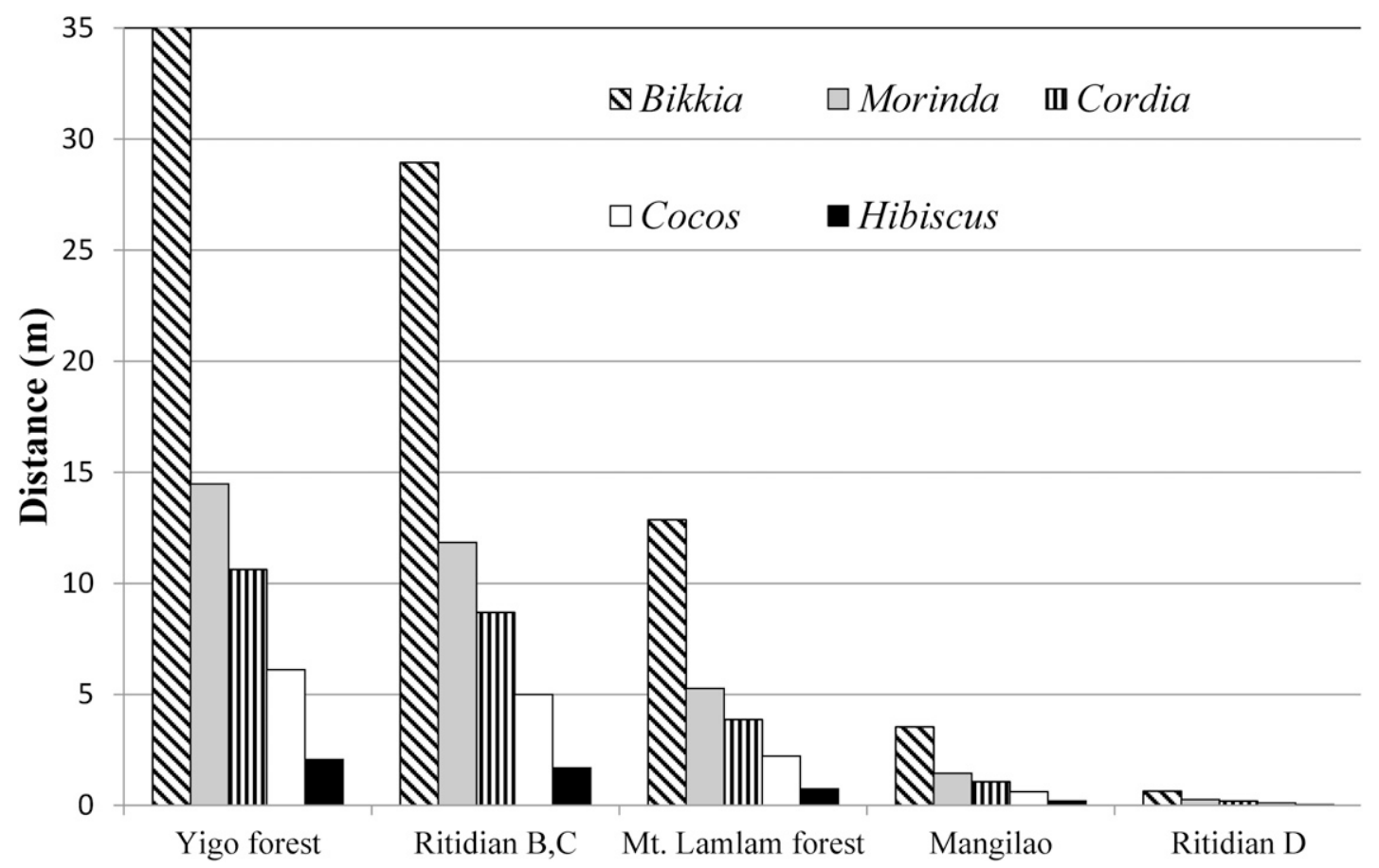

Fig. 8. Application of Eq. [1] illustrating the theoretical distance an individual pollen grain of each angiosperm can travel in these understory habitats before settling on a surface $1 \mathrm{~m}$ below the pollen source and subjected to mean constant wind velocity at each habitat (Table 3 ). (See Table 2 for mean settling velocities.)

2003; Motley et al., 2005; Razafimandimbison et al., 2012; Woodell, 1979).

Anemophily and ambophily examined. Several features of a plant's reproductive organs and pollen grains favor anemophilous pollination, and C. micronesica has many of these features. These include: copious production of pollen; reproductive structures produced in locations advantageous to pollen liberation or capture; high ratio of number of pollen grains to ovules; and female structures capable of capturing pollen and moving it to the ovule; smooth and buoyant pollen grains lacking pollenkitt (the lipid coating on pollen grains thought to aid in adhering pollen to animal pollinators; Dobson, 1988) (Roulston and Cane, 2000); and small grains with diameters less than $49 \mu \mathrm{m}$ (Ackerman, 2000; Culley et al., 2002; Friedman and Barrett, 2008; 2009; Niklas, 1985; Niklas and Norstog, 1984; Schwendemann et al., 2007).

Niklas and Norstog (1984) proposed additional lines of evidence for a role for wind in pollination of some cycads: 1) a decreasing seed set on females farther from males (although this can result in entomophilous species as well); 2) the similarity of most cycad reproductive structures to conifer ovulate cones; 3 ) the partially exposed nature of receptive ovules in some Cycas species; 4) and reproductive organs produced at the apex of tall Cycas plants that are in aerodynamically favored locations. Using wind tunnel experiments to examine the aerodynamics of windblown pollen around Cycas megasporophylls, Niklas and Norstog (1984) found that the probability of direct impaction of pollen grains on ovules is low but that numerous pollen grains adhere to the megasporophyll surfaces. A secondary vector such as insects or rain water has been proposed to carry the grains to the micropyle (Niklas and Norstog, 1984; Wang et al., 1997). Simulated rain did effectively transport pollen to ovules (Niklas and Norstog, 1984). Droplets secreted from the megasporophylls are also proposed to serve the same purpose as rain in transporting pollen to micropyles (Wang et al., 1997).

In contrast to absolute anemophily, plants that are ambophilous may increase their reproductive success by employing multiple pollen vectors (Culley et al., 2002), and by taking advantage of either pollination vector type under certain conditions. The evolution of wind pollination from entomophily has been documented in several angiosperm groups with a positive correlation between the evolution of anemophily and several environmental and biological factors including habitat exposure to wind and dioecy (Friedman and Barrett, 2008, 2009). Abiotic pollen vectors can be efficient at spreading pollen great distances and promote outcrossing (Carlquist, 1966), which is beneficial for small, genetically isolated populations. For cycads, especially those that disperse seeds via ocean currents enabling colonization of new locations, the reliance on specific animal pollinators can be an impediment to colonization if the new area is devoid of those pollinators (Barrett et al., 1996). Even for established plants that rely on a specific biotic pollen vector, there is a risk if pollinator populations become extinct or decline. This was illustrated in Cuban populations of Microcycas calocoma where the reduction of its insect pollinator population resulted in highly reduced seed set (Chavez and Ferrer, 2007).

Ambophily has been determined for some angiosperms (e.g., Costa and Machado, 2012; Culley et al., 2002; MeléndezRamírez et al., 2004); however, a better understanding of the partial role that wind may play in otherwise entomophilous plants is one of the major understudied issues in pollination biology, such that even establishing the number of plants that employ ambophily remains elusive (Mayer et al., 2011). Studies of several Cycas species (but including none from the $C$. rumphii species complex) suggest that insects are the major vectors, while wind may play a very minor role in pollination. For example, Kono and Tobe (2007) demonstrated ambophily in C. revoluta on Yonaguni Island, Okinawa, Japan. Wind was capable of vectoring pollen over a distance of only $2 \mathrm{~m}$, and the nitidulid beetle Carpophilus chalybeus vectored pollen regardless of the distance separating pollen and ovulate plants. A study of C. ophiolitica in Queensland, Australia, indicated that several beetle species were the primary vectors and pollen drift by wind was limited to very short distances $(\approx 5 \mathrm{~m})$ between trees (Hall, 2011). In a study of Lepidozamia peroffskyana, a cycad in the family Zamiaceae in which ovules are enclosed in a strobilus, Hall et al. (2004) concluded that specialist beetles are the only pollinators of this cycad and that wind plays essentially no role. Airborne pollen density 
trapped even at $0.5-2 \mathrm{~m}$ from a pollen source was very low and variable.

An ambophilous pollination system has been proposed for $C$. micronesica (Terry et al., 2009) wherein moths, beetles, and wind vector pollen between pollen trees and ovulate trees. This species has several plant traits similar to other entomophilous cycads: strobili are thermogenic; pollen strobili and megasporophylls produce odor and attract insects; and pollen strobili provide brood sites for moths (Roemer et al., 2013; Tang, 1987; Terry et al., 2005, 2009). The results of the current study and that by Hamada et al. (2015) demonstrate that in many Guam habitats, wind is capable of transporting single grains or clumps of $C$. micronesica pollen over distances that are typical of those between pollen and ovulate trees. Some ovules are exposed to wind-borne pollen, but for wind vectored pollen to reach less exposed ovules, secondary vectors of insects or rain may carry pollen to the micropyles, as suggested by Niklas and Norstog (1984). This may be a successful strategy in such an island colonizing dioecious plant where insect pollinators of mainland cycads may not easily cross oceans along with their plant propagules. Ongoing studies are suggesting that there is more evidence of the importance of both wind and insects in the pollination system of this environmentally valuable plant species.

\section{Literature Cited}

Ackerman, J.D. 2000. Abiotic pollen and pollination: Ecological, functional, and evolutionary perspectives. Plant Syst. Evol. 222:167-185.

Ashburner, G.R., M.G. Faure, E.A. James, W.K. Thompson, and G.M. Halloran. 2001. Pollination and breeding system of a population of tall coconut palms Cocos nucifera L. (Arecaceae) on the Gazelle Peninsula of Papua New Guinea. Pac. Conserv. Biol. 6:344-351.

Athens, J.S. and J.V. Ward. 2004. Holocene vegetation, savanna origins and human settlement of Guam, p. 15-30. In: V. Athenbrow and R. Fullager (eds.). A pacific odyssey: Archaeology and anthropology in the western pacific. Papers in honour of Jim Specht. Records of the Australian museum, Suppl. 29. Australian Museum, Sydney New South Wales, Australia.

Aylor, D.E. 2002. Settling speed of corn (Zea mays) pollen. Aerosol Sci. 33:1601-1607.

Aylor, D.E., N.P. Schultes, and E.J. Shields. 2003. An aerobiological framework for assessing cross-pollination in maize. Agr. For. Meteorol. 119:111-129.

Azmi, W.A., R. Ghazi, and N. Mohamed. 2012. The importance of carpenter bee, Xylocopa varipuncta (Hymineoptera: Apidae) as pollination agent for mangrove community of Setiu wetland, Terengganu. Sains Malays 41:10571062.

Barrett, S.C.H., B. Emerson, and J. Mallet. 1996. The reproductive biology and genetics of island plants [and discussion]. Philos. Trans. R. Soc. Lond. Ser. B Biol. Sci. 351(1341):725-733.

Carlquist, S. 1966. The biota of long-distance dispersal. IV. Genetic systems in the floras of oceanic islands. Evolution 20:433-455.

Chavez, R. and Y. Ferrer. 2007. Some news of Microcycas in Cuba. Cycad Nwsl. 30(4):10-14.

Costa, A.C.G. and I.C. Machado. 2012. Flowering dynamics and pollination system of the sedge Rhynchospora ciliata (Vahl) Kükenth (Cyperaceae): Does ambophily enhance its reproductive success? Plant Biol., doi:10.1111/ j. 1438-86677.2012.00574.x.

Culley, T.M., S.G. Weller, and A.K. Sakai. 2002. The evolution of wind pollination in angiosperms. Trends Ecol. Evol. 17:361-369.

Dehgan, B. and N.B. Dehgan. 1988. Comparative pollen morphology and taxonomic affinities in Cycadales. Amer. J. Bot. 75:1501-1516.

Dehgan, B. and C.K.K.H. Yuen. 1983. Seed morphology in relation to dispersal, evolution, and propagation of Cycas L. Bot. Gaz. 144:412-418.

Dobson, H.E.M. 1988. Survey of pollen and pollenkitt lipids - chemical cues to flower visitors? Amer. J. Bot. 75:170-182.

Donnegan, J.A., S.L. Butler, W. Grabowiecki, B.A. Hiserote, and D. Limtiaco. 2004. Guam's forest resources, 2002. Resource Bulletin PNW-RB243. U.S. Dept. Agr., Forest Serv., Pacific Northwest Res. Sta., Portland, Oregon.

Friedman, J. and S.C.H. Barrett. 2008. A phylogenetic analysis of the evolution of wind pollination in the angiosperms. Intl. J. Plant Sci. 169:49-58.

Friedman, J. and S.C.H. Barrett. 2009. Winds of change: New insights on the ecology and evolution of pollination and mating in windpollinated plants. Ann. Bot. (Lond.) 103:15151527.

Hall, J.A., G.H. Walter, D.M. Bergstrom, and P. Machin. 2004. Pollination ecology of the Australian cycad Lepidozamia peroffskyana (Zamiaceae). Aust. J. Bot. 52:333-343.

Hall, J.A. 2011. The ecology of cycads: Living representatives of an ancient plant lineage and their interactions with animals. Univ. of Queensland, Queensland, Australia, PhD Diss.

Hall, J.A. and G.H. Walter. 2011. Does pollen aerodynamics correlate with pollination vector? Pollen settling velocity as a test for wind versus insect pollination among cycads (Gymnospermae: Cycadaceae: Zamiaceae). Biol. J. Linn. Soc. Lond. 104:75-92.

Hamada, T., I. Terry, and T.E. Marler. 2015. Habitats, trade winds and pollination of the endangered Cycas micronesica: Is there a role for wind as pollen vector on the island of Guam? Intl. J. Plant Sci. 176:525-543.

Hedström, I. 1986. Pollen carriers of Cocos nucifera L. (Palmae) in Costa Rica and Ecuador (Neotrpoical region). Rev. Biol. Trop. 34:297301.

Hill, K.D. 1994. The Cycas rumphii complex (Cycadaceae) in New Guinea and the Western Pacific. Austral. Syst. Bot. 7:543-567.

Kevan, P.G. 1993. Wind or insects: Pollination of coconut (Cocos nucifera) in the Maldive Islands, p. 398-409. In: L.T. Conner, T. Rinderer, H.A. Sylvester, and S. Wongsiri (eds.). Asian apiculture. Wicwas Press, Cheshire, Conn.

Kono, M. and H. Tobe. 2007. Is Cycas revoluta (Cycadaceae) wind- or insect-pollinated? Amer. J. Bot. 94:847-855.

Lander, M.A. 1994. Meteorological factors associated with drought on Guam. Tech. Rpt no. 75 of the Water and Energy Research Institute of the Western Pacific, University of Guam, Mangilao, GU.

Lughadha, E.N. and C. Proenca. 1996. A survey of the reproductive biology of the Myrtoideae (Myrtaceae). Ann. Mo. Bot. Gard. 83:480-503.

Marler, T.E. and J.H. Lawrence. 2012. Demography of Cycas micronesica on Guam following introduction of the armoured scale Aulacaspis yasumatsui. J. Trop. Ecol. 28:233-242.
Marler, T.E. and R. Muniappan. 2006. Pests of Cycas micronesica leaf, stem, and male reproductive tissues with notes on current threat status. Micronesica 39:1-9.

Marler, T., J. Haynes, and A. Lindström. 2010. Cycas micronesica. The IUCN red list of threatened species. Version 2014.3. 23 Apr. 2015. <www.iucnredlist.org>.

Martin, M.D., M. Chamecki, G.S. Brush, C. Meneveau, and M.B. Parlange. 2009. Pollen clumping and wind dispersal in an invasive angiosperm. Amer. J. Bot. 96:1703-1711.

Mayer, C., L. Adler, W.S. Armbruster, A. Dafni, C. Eardley, S.Q. Huang, P.G. Kevan, J. Ollerton, L. Packer, A. Ssymank, J.C. Stout, and S.G. Potts. 2011. Pollination ecology in the 21st century: Key questions for future research. J. Pollination Ecol. 3:8-23.

McClatchey, W.C. 2003. Diversity of growth forms, and uses in the Morinda citrifolia L. complex, p. 5-10. In: S.C. Nelson (ed.). Proc. 2002 Hawai'i Noni Conference Univ. of Hawaii at Manoa, College of Tropical Agriculture and Human Resources.

Meléndez-Ramírez, V., V. Parra-Tabla, P.G. Kevan, I. Ramírez-Morillo, H. Harries, M. Fernández-Barrera, and D. Zizumbo-Villareal. 2004. Mixed mating strategies and pollination by insects and wind in coconut palm (Cocos nucifera L. (Arecaceae)): Importance in production and selection. Agr. For. Entomol. 6:155-163.

Moore, A., T. Marler, R.H. Miller, and R. Muniappan. 2005. Biological control of cycad aulacaspis scale on Guam. Cycad Nwsl. 28(5):6-8.

Motley, T.J., K.J. Wurdack, and P.G. Delprete. 2005. Molecular systematics of the CatesbaeeaeChiococceae complex (Rubiaceae): Flower and fruit evolution and biogeographic implications. Amer. J. Bot. 92:316-329.

Mylroie, J., J. Jenson, D. Taborosi, J. Jocson, D.T. Vann, and C. Wexel. 2001. Karst features of Guam in terms of a general model of Carbonate Island Karst. J. Caves Karst Stud. 63:9-22.

Nair, P.K.K. and M. Sharma. 1963. Pollen grains of Cocos nucifera Linn. Grana Palynologica 4:373-379.

Niklas, K.J. 1985. The aerodynamics of wind pollination. Bot. Rev. 51:328-386.

Niklas, K.J. and K. Norstog. 1984. Aerodynamics and pollen grain depositional patterns on cycad megastrobili: Implications on the reproduction of three cycad genera (Cycas, Dioon, and Zamia). Bot. Gaz. 145:92-104.

Niklas, K.J. and T.E. Marler. 2008. Sex and population differences in the allometry of an endangered cycad species, Cycas micronesica (Cycadales). Intl. J. Plant Sci. 169:659-665.

Razafimandimbison, S.G., S. Ekman, T.D. McDowell, and B. Bremer. 2012. Evolution of growth habit, inflorescence architecture, flower size, and fruit type in Rubiaceae: Its ecological and evolutionary implications. PLoS One 7(7): 40851.

Roemer, R.B., L.I. Terry, and T.E. Marler. 2013. Cone thermogenesis and its limits in the tropical Cycas micronesica (Cycadaceae): Association with cone growth, dehiscence, and post-dehiscence phases. Amer. J. Bot. 100:19811990.

Rogers, R.F. 2011. Destiny's landfall: A history of Guam. Univ. Hawaii Press, Honolulu, HI.

Roulston, T.H. and J.H. Cane. 2000. Pollen nutritional content and digestibility for animals. Plant Syst. Evol. 122:187-209.

Schwendemann, A.B., G. Wang, M.L. Mertz, R.T. McWilliams, S.L. Thatcher, and J.M. Osborn. 2007. Aerodynamics of saccate pollen and its 
implications for wind pollination. Amer. J. Bot. 94:1371-1381.

Stevenson, D.W., K.J. Norstog, and P.K.S. Fawcett. 1998. Pollination biology of cycads, p. 277-294. In: S.J. Owens and P.J. Rudall (eds.). Reproductive biology. Royal Botanic Gardens, Kew, UK.

Tang, W. 1985. Collecting and storing cycad pollen. Cycad Nwsl. 8(2):10-12.

Tang, W. 1987. Heat production in cycad cones. Bot. Gaz. 148:165-174.

Tang, W. 2004. Cycad insects and pollination, p. 383-394. In: P.C. Srivasiava (ed.). Vistas in paleobotany and morphology: Evolutionary and environmental perspectives, Professor D.D. Pant Memorial Vol. U.P. Offset, Lucknow, India.

Terry, L.I. 2001. Thrips and weevils as dual, specialist pollinators of the Australian cycad Macrozamia communis (Zamiaceae). Intl. J. Plant Sci. 162:1293-1305.

Terry, L.I., G.H. Walter, J.S. Donaldson, E. Snow, P.I. Forster, and P.J. Machin. 2005. Pollination of Australian Macrozamia cycads (Zamiaceae): Effectiveness and behavior of specialist vectors in a dependent mutualism. Amer. J. Bot. 92:931-940.

Terry, I., M. Roe, W. Tang, and T.E. Marler. 2009. Cone insects and putative pollen vectors of the endangered cycad, Cycas micronesica. Micronesica 41:83-99.

Timerman, D., D.F. Greene, J.D. Ackerman, P.G. Kevan, and E. Nardone. 2014. Pollen aggregation in relation to pollen vector. Intl. J. Plant Sci. 175:681-687.

Wang, Q., C.L. Li, S.Y. Yang, R. Huang, and F.L. Chen. 1997. Pollination biology of Cycas panzhihuaensis L. Acta Bot. Sin. 39(2):156-163.

Woodell, S.R.J. 1979. The role of unspecialized pollinators in the reproductive success of Aldabran plants. Philos. Trans. R. Soc. Lond. Ser. B Biol. Sci. 286:99-108. 